Review

\title{
The Role of Self-Compassion in Recovery from Substance Use Disorders
}

Gila Chen *

Gila Chen (Ph.D.) is an associate professor in the Department of Criminology at Ashkelon Academic College, Israel. In addition to her academic roles, Professor Chen is a Short-term psychotherapist.

Ashkelon Academic College, 12 Ben Tzvi St, Israel; E-Mail: gilhcn@edu.aac.ac.il

* Correspondence: Gila Chen; E-Mail: Chengila6@gmail.com

Academic Editor: Steven K. H. Aung

Special Issue: $\underline{\text { How Compassion Benefits in the Healing Process }}$

OBM Integrative and Complementary Medicine

2019, volume 4, issue 2

doi:10.21926/obm.icm.1902026
Received: March 04, 2019

Accepted: April 17, 2019

Published: April 24, 2019

\begin{abstract}
Background: A large body of empirical evidence has supported the notion that individuals with substance use disorders (SUDs) have difficulty regulating their negative emotions and employing emotion-regulation strategies. The aim of this article is to (a) explore the role of self-compassion in providing an emotion-regulation strategy for initiating a process of recovery from SUDs; (b) examine the role of self-compassion in building recovery capital (RC) to promote long-term recovery; and (c) examine the practice of self-compassion in the Alcoholics Anonymous (AA) and Narcotics Anonymous (NA) programs.
\end{abstract}

Methods: This narrative review assesses the role of self-compassion in providing an emotionregulation strategy and in building RC to initiate and promote long-term recovery.

Results: Empirical evidence has shown self-compassion to be an emotion-regulation strategy in which negative feelings are accepted and held with awareness, kindness, understanding, and a sense of common humanity. Based on the broaden-and-build theory, I posit that self-

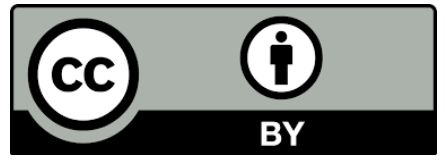

(C) 2019 by the author. This is an open access article distributed under the conditions of the Creative Commons by Attribution License, which permits unrestricted use, distribution, and reproduction in any medium or format, provided the original work is correctly cited. 
compassion as a positive emotional stance towards oneself enables the development of personal and social resources. The prospects for successful recovery from SUDs are dependent upon the individual's resources, which Granfield and Cloud referred to as RC.

Conclusions: This article may contribute to the field by presenting the role of self-compassion in building RC to initiate and promote long-term recovery from SUDs and by discussing the practice of self-compassion in the AA and NA programs.

\section{Keywords}

Self-compassion; emotion regulation; recovery capital; recovery; substance use disorders

\section{Introduction}

A large body of empirical evidence has supported the notion that individuals with substance use disorders (SUDs) have difficulty regulating their emotions, and that negative emotional states precipitate SUDs [1, 2]. Moreover, findings have shown that it is more difficult for individuals with SUDs to understand and identify their emotions $[3,4]$ and to employ emotion-regulation (ER) strategies [1,5]. Furthermore, there is also evidence that positive emotions help with self-regulation deficits [6].

Self-compassion is a positive emotional stance towards oneself [7]. Numerous studies have found self-compassion to correlate positively with positive affect and negatively with negative affect [8-10]. Moreover, Neff $[7,11]$ posited that self-compassion is an ER strategy in which the individual accepts negative feelings with awareness, kindness, understanding, and a sense of common humanity. Thus, in times of suffering and distress, self-compassion helps transform negative emotions into more positive ones [12]. In a similar vein, according to the broaden-and-build theory, positive emotions have the ability to amend the effects of negative emotions, broaden one's thought-action repertoires, and build personal resources over time $[13,14]$. Therefore, it is reasonable to suggest that selfcompassion enables individuals to build personal and social resources, such as recovery capital (RC), and, in turn, to initiate and sustain long-term recovery from SUDs.

In light of the above, the present article is devoted to (a) exploration of the role of self-compassion in providing an ER strategy to initiate a process of long-term recovery from SUDs; (b) investigation of the role of self-compassion in building RC to initiate and promote long-term recovery; and (c) examination of the practice of self-compassion in the Alcoholics Anonymous (AA) and Narcotics Anonymous (NA) programs. This article is divided into four sections. The first is a survey of the existing empirical research on ER and SUDs. The second provides a narrative review of the literature on self-compassion as an ER strategy and an emotionally positive self-attitude that builds RC as a means of initiation and promoting long-term recovery from SUDs. The third section offers an examination of the practice of self-compassion by members of NA and AA programs as a means to build RC that enables long-term recovery, and the final section presents the conceptual model of the current article. 


\subsection{Emotion Regulation and SUDs}

Emotion regulation (ER) has become a central concept in psychophysiology and modern psychotherapy. ER is regarded as an essential psychological capacity, consisting of three primary cognitive, emotional, and behavioral dimensions: the ability to exhibit self-control, the ability to tolerate distress, and the ability to self-monitor and integrate awareness of emotions [15]. ER represents the processes of individual emotion management [16], subjective expression of experiences [17], and adaptive coping with negative emotional states [18]. ER skills are essential for a range of related capacities, including stress management, interpersonal functioning, development of cognitive problem solving, and communication skills. Expressions of deficits in ER include mood and anxiety disorders, maladaptive strategies to regulate negative emotions (e.g., avoidance or substance use), behavioral impulsivity, difficulty in delaying gratification, instability of behavioral control, and affective liability, each of which is further perpetuated by negative life events [4].

Theoretical models of ER difficulties among individuals with maladaptive behaviors, such as SUDs, violent crimes, or eating disorders, have indicated childhood maltreatment as a significant factor that could predispose or intensify emotion dysregulation, which is associated with other mental health problems later in life [19-22]. For example, in a study of youth with substance use difficulties, Vettese, Dyer, Li, and Wekerle found that child abuse was positively associated with ER difficulties and negatively associated with self-compassion [23]. This inability to manage emotions may result in unregulated distress, encouraging patterns of avoidance, rumination, self-harm, suppression of emotions, and harmful behaviors in an attempt to manage emotions [24]. Emotional consequences of childhood maltreatment include maladaptive views toward self and others, such as shame, selfcriticism, loneliness, dissociation, and sense of isolation from both people and emotions [25, 26].

Self-criticism and shame play a central role in causing distressing emotions such as anxiety, guilt, anger, and self-hatred, which result from self-appraisal as unwanted, unworthy, and inadequate. Shame relates to global, negative feelings about the self, and has been described as an intense negative emotion that can result in feelings of inferiority and powerlessness [27]. It has been strongly implicated in behaviors that enable individuals to escape feelings of worthlessness and failure, such as disordered eating and SUDs [28]. Heightened shame and self-criticism significantly increase vulnerability to addictive behaviors, particularly substance use, in an attempt to avoid or eliminate these unwanted thoughts and feelings $[27,29]$.

Maladaptive behaviors are a form of self-medication to regulate negative affect [30]. The selfmedication hypothesis is a well-known substance use model developed to explain the impact of trauma exposure on the development of SUDs [31]. According to this hypothesis, individuals with a history of trauma and post-traumatic stress disorders (PTSD) may experience a lack of resources to cope with trauma and manage negative emotions that persist over time, and turn to substance use to soothe themselves, modulate the effects of distressful psychological states, and relieve painful emotions (anger and sadness) or physical sensations (hyperarousal in individuals with PTSD).

Emotional deficiencies, which cause suffering, may motivate individuals to seek solace through substance use as a form of self-treatment [32]. Suh et al. [33] found a significant association between using substances and difficulty managing emotional states, which indicates a co-occurrence of SUDs 
and ER deficits. Experiencing rage, shame, loneliness, self-alienation, emptiness, depression, and anxiety as intolerable emotions can drive individuals to use substances in order to regulate and maintain their emotional states [31].

Self-regulation plays a central role in managing, controlling, and coordinating emotion, cognition, and behavior. According to the ER models, fundamental difficulties coping with experiences and emotions are core factors of depression and anxiety disorders [34]. Difficulties in self-regulation cut across multiple diagnostic domains and reflect broad classes of maladaptive psychosocial functioning and behaviors, including SUDs. Several scholars have suggested that a primary focus in mental health and substance use treatment intervention should be the improvement of ER skills, in order to treat SUDs effectively $[15,25,35]$. There is evidence that positive emotions help replenish a depleted sense of self-regulation, making it possible once again to control behaviors [6]. Thus, Odou and Brinker [36] found that the self-compassion strategy is valuable for recovery from SUDs and may enhance one's regulation of emotions or behaviors, especially when experiencing distress.

\subsection{Self-Compassion}

"If you don't love yourself, you cannot love others. You will not be able to love others. If you have no compassion for yourself then you are not able of developing compassion for others" -Dalai Lama.

Compassion is the state of being aware of and affected by the suffering of others, feeling kindness toward their suffering, and attempting to alleviate it [7]. However, having compassion for others but not oneself is futile, since the self and others are integrated in a common humanity. Thus, selfcompassion involves a sense of common humanity, being caring and compassionate toward one's own suffering and distress, which drives a desire to alleviate and heal one's own suffering with kindness, understanding, and recognition that all humans are imperfect and make mistakes. In a similar vein, Kurtz and Ketcham wrote, "Spirituality begins with the acceptance that our fractured being, our imperfection, simply is: there is no one to "blame" for our errors - neither ourselves nor anyone nor anything else. Spirituality helps us first to see, then to understand, and eventually to accept the imperfection that lies at the very core of our human be-ing" [37].

Neff's conceptualization of self-compassion is grounded in the Buddhist tradition of well-being, which focuses on understanding the self. Neff [7, 38] described self-compassion as a healthy form of self-acceptance that includes acceptance of one's painful experiences, along with a desire to lessen the pain and treat oneself with kindness. Neff $[7,38]$ described self-compassion as composed of three positive-response (compassionate) and three negative-response (uncompassionate) dimensions: selfkindness versus self-judgement, common humanity versus isolation, and mindfulness versus overidentification. Self-kindness is being emotional, warm, kind, and supportive to oneself rather than judging oneself harshly or being self-critical during times of difficulty. A sense of common humanity is the recognition that life's difficulties are part of shared human experience, rather than viewing them as isolating, separating, or the plight of just some people. Acknowledging that suffering and distress are part of the human condition enables individuals to see the similarity between their own experiences and those of others. Moreover, common humanity promotes a sense of connectedness with others, thereby lessening feelings of isolation. Mindfulness is being aware of painful thoughts 
and feelings instead of being completely absorbed in them. It refers to a balanced approach to negative emotions, which neither suppresses nor exaggerates them. Gilbert proposed an alternative theoretical approach of self-compassion that is rooted in the evolutionary model of social mentality theory [25]. He conceptualized self-compassion as a social motivation that involves skills and attributes of compassion [39, 40], such as non-judgmental concern for one's well-being rather than taking a condemning, self-critical stance; empathy for the suffering of others or oneself; sensitivity; distress tolerance and understanding of one's painful feelings and memories rather than self-criticism or avoidance; and development of self-warmth [41].

Self-compassionate individuals do not repress or avoid painful feelings; they acknowledge and feel compassion without over-identifying with them [7]. In times of suffering, self-compassion helps transform negative emotions into a more positive state and facilitates more effective coping with one's own problems and/or the environment $[12,42,43]$. It is based on components of ER (e.g., awareness and accepting emotions) and requires individuals to experience and explore their negative emotions [7]. Therefore, self-compassion can be an effective emotion-regulation strategy, enabling the processing and acceptance of emotional pain by means of paying full attention to thoughts and feelings and treating them with understanding [11]. During times of distress, self-compassion acts as an adaptive emotion-regulation strategy that promotes psychological health by decreasing selfcriticism, a sense of isolation, alienation, and avoidance of painful experiences, thoughts, and emotions [7, 44, 45]. Furthermore, the self-compassion approach encourages a sense of connection with others, which protects individuals against isolation, loneliness, and shame, characteristics of maladaptive emotional response [34]. Similarly, Gilbert [25,39] proposed that self-compassion may play a significant role in facilitating the use of more adaptive ER strategies; strengthening a selfcompassionate stance improves the regulation of emotional responses to perceived threats. Better self-soothing leads to enhanced ER, because it reduces sensitivity to threats, and increases the ability to effectively access, tolerate, and express emotions. Thus, self-compassion builds emotional resilience by neutralizing the threat system that generates insecure attachment, defensiveness, and autonomic arousal [25].

According to Gilbert, compassion flows in three directions: towards another person, which represents its most basic focus; from others towards oneself; and towards oneself (self-compassion) [39]. Any of these dimensions can be a focus in Gilbert's compassion focused therapy (CFT). Based on neuroscientific evidence, it was developed for people with high levels of shame, self-criticism, and unkindness and unsupportive attitudes toward themselves. CFT focuses on developing "competencies and brain systems that play important roles in threat regulation, well-being, and prosocial behavior" (p. 33). It addresses three types of affect-regulation systems: the threat-and-protective system, the resource-seeking and drive system, and the contentment, safety, and soothing system [40]. According to the underlying theory of CFT, psychopathology is an expression of unbalanced systems of affect regulation, which are rooted in attachment relationships [40]. In this case, the threat-based system is activated disproportionately, and the contentment, safety, and soothing system is often relatively inactive [46]. Conversely, individuals with a high level of self-compassion have a greater capacity to activate and maintain positive affective experiences associated with the soothing system, such as feelings of safety, affiliation, and warmth [47]. 


\subsection{Self-Compassion and SUDs}

There is a growing body of empirical evidence that demonstrates an association between emotion dysregulation and SUDs $[48,49]$. It has been posited that one of the main motives for substance use is the avoidance of negative emotions, such as anxiety and depression [50]. According to Kober's model [51], substances are capable of regulating negative emotions through their unique pharmacological characteristics and their ability to bring about positive affective states, which in turn reinforce increased substance use. The high prevalence of emotion dysregulation among substance users suggests the potential of incorporating ER training into substance-use treatment. Against this background, teaching individuals with SUDs how to respond to their emotions more adaptively and providing self-compassion-based therapy could be beneficial.

Despite the robust empirical evidence that self-compassion can help in developing effective ER skills to cope with the characteristic negative emotions of people with SUDs $[8,11,52]$, the research on the relationship between self-compassion and SUDs is limited. In a review of the literature pertaining to self-compassion, Finlay-Jones found that self-compassion is linked to key mechanisms of the ER models of depression and anxiety [34].

The few studies published to date show a negative association between self-compassion and alcohol use disorders $[53,54]$. For example, in an investigation of the correlation between selfcompassion and alcohol use among 77 participants in Australia, Brooks et al. found that initially, participants scored significantly lower than the general population on the positive subscales of selfcompassion, self-kindness, common humanity, and mindfulness, and significantly higher on the negative subscales of over-identification, isolation, and self-judgment [53]. After 15 weeks in a treatment program that included a range of clinical interventions (community counselling, detoxification, needle and syringe programs, and more), there was a significant increase in selfcompassion, mindfulness, common humanity, and self-kindness compared with the findings at the beginning. Furthermore, there was a significant decrease in self-judgment, isolation, overidentification, and alcohol use, which was associated with an increase in self-compassion. In another study, Rendon examined the relationship between alcohol use, self-compassion, mindfulness, and self-esteem among 300 psychology students in United States [54]. The results indicated that alcohol use was negatively correlated with self-esteem, self-compassion, and psychological symptoms. In addition, self-compassion was found to be a predictor of psychological health.

Summarizing the literature reviewed above, it seems that individuals with SUDs are characterized by ER deficits, and uncompassionate ways of responding, including (a) shame; (b) self-criticism; (c) negative emotions (depression, anxiety, hostility); and (d) loneliness, isolation, and alienation. A limited body of research has examined the relationship between self-compassion and SUDs. Nevertheless, it is reasonable to argue that self-compassion techniques and therapies might initiate and promote long-term recovery from SUDs through effective ER strategies that enable the acceptance of emotional pain and compassionate treatment of thoughts and feelings. 


\subsection{Self-Compassion Builds Recovery Capital}

Research has shown a negative correlation between self-compassion and negative emotions, such as anger $[8,10]$, and a positive correlation between self-compassion and positive emotions, such as happiness, optimism, love, and conscientiousness [9]. Positive emotions are associated with multiple interrelated benefits, beyond the pleasant subjective feeling; these include broadened cognition, enhanced creativity, increased productivity, and improved physical and mental health [55]. In her broaden-and-build theory, Fredrickson argued that positive emotions such as joy, interest, contentment, and love are capable of alleviating the effects of negative emotions $[13,14,56]$. They broaden one's thought-action repertoires, and, over time, build personal resources, ranging from the physical and intellectual to the social and psychological, all of which can contribute to an overall sense of well-being. These personal resources function as reserves that can be drawn on in subsequent moments and in different emotional states. Thus, positive emotions may be adaptive in the long term, by building personal resources that function as psychological reserves for continued growth. A review of the literature on interventions based on self-compassion suggest considerable alleviation of negative affect [8], promotion of emotional resilience [57], enhancement of sense of well-being by helping individuals feel cared for, connected, and emotionally calm [47], and improvement and strengthening of interpersonal relationships, social connectedness, and sense of belonging $[58,59]$.

This new theoretical perspective on positive emotions is part of the positive psychology field, which shifts attention from pathology and dysfunction to positive emotions and optimal functioning. In positive psychology, positive emotions are seen as a means to achieving a long-term sense of wellbeing and psychological growth [56]. Neff's conceptualization of self-compassion represents a positive emotional stance towards oneself, characterized by kindness and caring. High levels of selfcompassion often generate positive emotions, which contribute to higher rates of psychological wellbeing and life satisfaction [9]. Both of these areas of focus are based on the fundamental view that health is more than the absence of illness and that fostering individual and social resources can help people, organizations, and communities thrive [56,60]. Similarly, a comprehensive vision of global health (wellness) views long-term recovery from SUDs as far more than simply the alleviation of the symptoms of substance use. The focus is on moving beyond the reduction of substance use-related pathology to the creation of personal, family, and community resources.

Based on the broaden-and-build theory, in the present article I posit that self-compassion is an emotionally positive self-attitude that enables individuals to build personal and social resources, that is, RC, to overcome SUDs. RC is a comprehensive concept for understanding the wide range of personal and social resources that are required in the effort to initiate and sustain long-term recovery from SUDs. The term was first used by Cloud and Granfield to denote the key personal and social resources necessary to initiate and sustain recovery [61]. Cloud and Granfield identified four components of RC [61]. The first is cultural capital, which refers to the values and beliefs associated with cultural group membership, such as AA or NA. The second is physical capital, which includes financial assets and status, especially housing (shelter), clothing, and food. Third is human capital, which comprises the acquired and inherited traits - such as knowledge, skills, and mental health that enable individuals to function effectively in society and face the challenges of the recovery effort. 
The fourth component is social capital, which includes various close (especially family) relationships that are supportive of recovery efforts. It has been suggested that individuals with social capital are in a much better position to initiate and maintain successful recovery [62]. This comprehensive view of recovery represents the interconnectedness of all aspects of the individual's life that enable successful reintegration into society. It is the thesis of the current article that AA and NA members practice self-compassion as a means to build RC, which in turn enables them to initiate and sustain long-term recovery.

\subsection{The Practice of Self-Compassion in AA and NA Programs}

There is no research on the practice of self-compassion in AA and NA programs, but selfcompassion is a central component in their processes for initiation and promotion of long-term recovery. The novel contribution of the current article to the literature is in describing the practice of self-compassion in AA and NA programs, and in presenting meaningful examples of AA and NA statements which support the concept of self-compassion. In NA's Basic Text [63], a member is quoted as saying, "In the Eighth Step, I made a list of people whom I had harmed, and I put myself first on the list. I hurt a lot of people, but none as much as I hurt myself. I had nothing but contempt for myself, so there was no limit to the pain I inflicted on myself... Instead of inflicting more hurt, I practice love, compassion, and forgiveness" (p. 226). Neff argued that engaging in negative thinking towards the self is common; people are often much harsher and unkinder toward themselves than toward others [57]. Self-compassion requires recognition of one's own suffering and being caring, kind, and compassionate toward one's own suffering and distress, rather than reacting critically and judgmentally. This eventually helps foster "positive mind states such as happiness and optimism" [57]. In other words, self-kindness includes working actively towards understanding our shortcomings, defects, and failures. In this spirit, Kurtz and Ketcham wrote, "It is only by ceasing to play God, by coming to terms with errors and shortcomings, and by accepting the inability to control every aspect of their lives alcoholics can find peace" [37].

Self-compassion is the foundation for feelings of self-acceptance. In fact, it provides individuals with what Ellis referred to as "unconditional self-acceptance," where the "individual fully and unconditionally accept[s] himself whether or not he behaves intelligently, correctly, or competently and whether or not other people approve, respect or love him" [64]. This is key to psychological wellness. Developing increased acceptance and positive emotions along with lower negative emotions by relating to oneself in a compassionate way enables more adaptive regulation of painful emotions [34]. Members of AA and NA view their recovery as a long-term process of self-acceptance: "I had no idea the solution would begin with acceptance of myself. From this position, I naturally developed the capacity to accept and care about others" [63]. Self-acceptance is important in providing emotional safety, which in turn enables one to see the self clearly without feeling ashamed or guilty, and to foster a sense of social connectedness. Another member explained, "At last, acceptance proved to be the key to my drinking problem. After I had been around AA for seven months ... I was finally able to say...I really, really am an alcoholic of sorts. And it's all right with me. 
From that moment on, I have not had a single compulsion to drink. And acceptance is the answer to all my problems today" [65].

Other members referred to the shame and guilt that characterize individuals with SUDs [66]: "For years, we avoided seeing ourselves as we really were. We were ashamed of ourselves and felt isolated from the rest of the world. Now that we have the shameful part of our past trapped, we can sweep it out of our lives if we face and admit it" [63]. Self-acceptance enables recovering individuals with SUDs to cope with the feelings of shame and guilt that cause them to feel alone, isolated, and like they don't belong. Experiencing shame harshly attacks individuals' selves, causing them to feel unlovable, and leading to desires to withdraw or escape from others, which leaves them alienated and alone with their distress: "Everything was controlled by the drugs. I felt shame and guilt and would regularly judge and punish myself" [63]. Conversely, self-compassion provides individuals with a sense of being gentle and self-forgiving, being kind rather than judging harshly or being self-critical: "One thing that really helped was when I started to realize that all the criticism was coming from inside me, and that what I was getting from the people around me in meetings was encouragement and approval" [63], or as another member put it: "I have never experienced anything like that night. I expected judgment and criticism, but what I actually received was nothing but love. I was embraced by the addicts in that room" [63].

Moreover, self-compassion does not separate the self from others, but integrates the individual with others in a common humanity [7]. Thus, an effective way to increase self-compassion is by giving compassion to others [67]: "Learning his secret gave me more compassion for my father-and more compassion for myself. I have a disease that has occurred in my family several times. I did not choose to be addicted. I am unable to take the disease away" [63]. Self-compassion provides individuals with a sense of common humanity, and understanding of life's difficulties as a part of a shared human experience; this promotes a sense of connectedness with others, thereby lessening feelings of isolation.

AA and NA activities also include prayers and meditation. In Step 11, the members are asked to connect with their "higher power," as an act of self-love through prayer and/or meditation. According to members, prayers and meditation increase compassionate responses toward oneself and others, which in turn transform negative emotions into positive emotions that have the ability to "correct" the effects of negative emotions [13, 14]: "Even when you don't really want it for them and your prayers are only words and you don't mean it, go ahead and do it anyway. Do it every day for two weeks, and you will find you have come to mean it and to want it for them, and you will realize that where you used to feel bitterness and resentment and hatred, you now feel compassionate understanding and love" [63].

Mindfulness is the final component of self-compassion. Mindfulness emphasizes the need to take a balanced approach to negative emotions, to acknowledge, and to feel compassion for them, without over-identifying with their feelings [7, 38]. Learning to be mindful promotes greater emotional balance, in that it "allows us to distinguish between those aspects of our experience we can change and those we can't" [57]. This concept can also be associated with the "serenity prayer," which was written by Niebuhr in 1926 [68] and is widely used in the AA and NA programs, "God grant me the serenity to accept the things I cannot change; courage to change the things I can; and wisdom to 
know the difference." This prayer teaches members the wisdom to distinguish one from the other (acceptance versus change), "which comes with growth in our spiritual program" [63]. Thus the members of AA and NA practice mindfulness, as embodied in the prayer. By means of maintaining such a balanced approach and by allowing expression of both negative and positive emotions, "we learn how to level out the emotional swings that got us into trouble both when we were up and when we were down" [65]. Another member stated, "I listened as people shared their experience. What fascinated me was the ability of NA members to express their feelings, good and bad" [63].

Newcombe examined the relationship between different aspects of the AA program and levels of shame and self-compassion among 148 active AA members [69]. The findings indicated positive correlations between level of engagement in $A A$, length of time attending meetings, time clean, and self-compassion. The AA activities that best predicted lower shame and higher self-compassion included engagement in social activities outside of AA meetings, meeting with sponsors, and speaking at meetings. In addition, participants who completed Step 5 (sharing with another human being) and Step 9 (make amends) had significantly lower levels of shame and higher levels of self-compassion than those who had not completed those steps. Moreover, sharing the message with another suffering addict or with the group (Step 12) has been shown to give the messengers meaning in life, which is an expression of spiritual growth and the individual's sense of wholeness [70].

\section{The Conceptual Model}

According to the conceptual model of the present article (see Figure 1), self-compassion is a positive emotional stance towards oneself that enables individuals to build recovery capital to initiate long-term recovery. My underlying assumption in developing this model was based on the broadenand-build theory $[13,14]$, which views positive emotions as having the ability, over time, to repair the effects of negative emotions and build personal resources, ranging from physical and intellectual to social and psychological resources. These personal resources serve as reserves that can be drawn from in different emotional states

The practice of self-compassion in AA and NA programs activates two stages of recovery, early recovery initiation and long-term recovery process. Self-compassion can initiate an early recovery process by transforming negative emotions into positive emotions, thereby promoting a sense of wellness. In addition, self-compassion promotes a long-term recovery process, by building RC, including social capital (by strengthening a sense of common humanity, social connectedness, and interpersonal relationships versus a sense of isolation and alienation, which characterize individuals with SUDs), human capital (by serving an effective emotional regulation strategy because it enables emotional pain to be accepted and held with kindness, in turn promoting mental health and wellbeing), and spiritual growth (by sharing the message with other suffering addicts (Step 12), which provides one with a sense of meaning in life). 


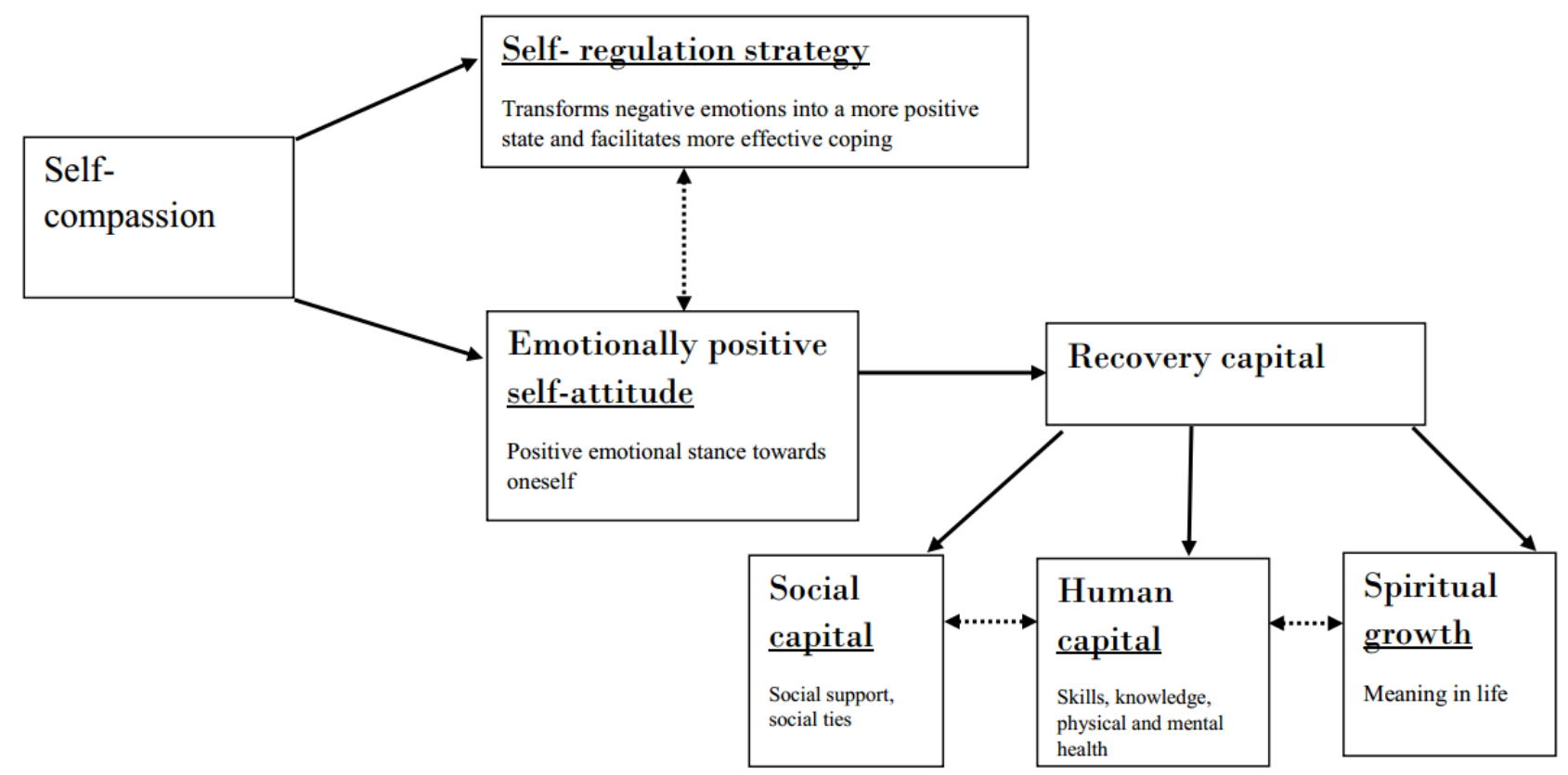

Figure 1 Self-compassion enables individuals to build recovery capital and to initiate and maintain long-term recovery from SUDs.

\section{Conclusions}

Self-compassion is an essential component of physical and mental wellness and fits in well with the comprehensive vision of long-term recovery from SUDs, which refers to the attainment of physical, psychological, relational, and spiritual health recovery that represents the interconnectedness of all aspects of the individual's life [71]. Self-compassion as a holistic wellness also fits well with the World Health Organization's definition of health as "a state of complete physical, mental, and social wellbeing" [72].

Self-compassion can be perceived as an ER strategy that promotes emotional balance in stressful situations that otherwise might create the ER difficulties that characterize individuals with SUDs. It enables improvement and strengthening of interpersonal relationships, social connectedness, and a sense of belonging, rather than the sense of loneliness and alienation common among individuals with SUDs. Moreover, as an emotionally positive self-attitude, self-compassion enables individuals to build RC - the wide range of personal and social resources that are required in the effort to achieve long-term recovery from SUDs.

\subsection{Implications and Future Research}

Self-compassion interventions have shown effective results in general and clinical research [25, 73, 74]. Moreover, self-compassion intervention is a helpful tool, with a variety of potential beneficial psychological outcomes in diverse fields, including trauma, post-traumatic stress disorder, depression, anxiety, neurotic perfectionism, and sense of personal failure. Accordingly, Neff noted, 
"Remembering that suffering and personal failure happen to all people helps put one's experience into perspective, also enhancing the ability to be mindful of one's thoughts and emotions and to not over-identify with them" [38].

Given the many positive outcomes that self-compassion intervention has been associated with in research in the field, it seems that effective therapeutic intervention in long-term recovery from SUDs should integrate self-compassion interventions. To this end, it should include: (a) assessment of one's self-compassion, using tools such as Neff's six-part self-compassion scale (SCS), in which three parts test the positive aspects and the other three, the negative aspects of her construct [38]; (b) targeting of those who score on the low-to-lowest level of self-compassion, in order to provide appropriate intervention; and (c) strengthening the individual's self-compassion by encouraging participation in AA or NA programs, and other self-compassion interventions, such as CFT [40].

To conclude, several scholars in the field of substance use have noted that the concept of RC reflects a shift in focus from the pathology of SUDs to a strengths-based paradigm that focuses on the internal and external resources required to initiate and sustain long-term recovery [75]. This article contributes to the field by presenting the role of self-compassion in building $\mathrm{RC}$ to initiate and promote long-term recovery from SUDs. Further research is necessary to investigate how RC can advance the capacity of individuals to overcome problems related to substance use and the significance of other key components, such as hope and forgiveness, as RC.

\section{Author Contributions}

Gila Chen is sole author of this work.

\section{Acknowledgments}

The author would like to acknowledge Dr. Kristin Neff, whose work helped inspire this article.

\section{Funding}

I declare that I have had no funding resources or grant for this article.

\section{Competing Interests}

The author has declared that no competing interests exist.

\section{References}

1. Aldao A, Nolen-Hoeksema S, Schweizer S. Emotion-regulation strategies across psychopathology: A meta-analytic review. Clin Psychol Rev. 2010; 30: 217-237. doi:10.1016/j.cpr.2009.11.004

2. Fox HC, Axelrod SR, Paliwal P, Sleeper J, Sinha R. Difficulties in emotion regulation and impulse control during cocaine abstinence. Drug Alcohol Depen. 2007; 89: 298-301. 
3. Fox HC, Hong KI, Siedlarz K, Sinha R. Enhanced sensitivity to stress and drug/alcohol craving in abstinent cocaine-dependent individuals compared to social drinkers. Neuropsychopharmacol. 2008; 33: 796-805.

4. Willis TA, Pokhrel P, Morehouse E, Fenster B. Behavioral and emotional regulation and adolescent substance use problems: A test of moderation effects in a dual-process model. Psychol Addict Behav. 2011; 25: 279-292.

5. Pierrehumbert B, Bader M, Miljkovitch R, Mazet $P$, Amar M, Halfon O. Strategies of emotion regulation in adolescents and young adults with substance dependence or eating disorders. Clin Psychol Psychot. 2002; 9: 384-394.

6. Tice DM, Baumeister RF, Shmueli D, Muraven M. Restoring the self: Positive affect helps improve self-regulation following ego depletion. J Exp Soc Psychol. 2007; 43: 379-384.

7. Neff KD. Self-compassion: An alternative conceptualization of a healthy attitude toward oneself. Self Ident. 2003; 2: 85-101. doi: http://dx.doi.org/l0.1080/15298860309032

8. Leary MR, Tate EB, Adams CE, Allen AB, Hancock J. Self-compassion and reactions to unpleasant self-relevant events: the implications of treating oneself kindly. J Pers Soc Psychol. 2007; 92: 887904.

9. Neff KD, Rude SS, Kirkpatrick KL. An examination of self-compassion in relation to positive psychological functioning and personality traits. J Res Pers. 2007; 41: 908-916. doi: http://dx.doi.org/10.1016/j.jrp.2006.08.002

10. Neff KD, Vonk R. Self-compassion versus global self-esteem: Two different ways of relating to oneself. J Pers. 2009; 77: 23-50. doi:http://dx.doi.org/10.111l/j.1467-6494.2008.00537.x

11. Neff KD. Self-compassion and psychological well-being. Construct Human Sci. 2004; 9: 27-37.

12. Roemer L, Lee JK, Salters-Pedneault K, Erisman SM, Orsillo SM, Mennin DS. Mindfulness and emotion regulation difficulties in generalized anxiety disorder: Preliminary evidence for independent and overlapping contributions. Behav Ther. 2009; 40: 142-154.

13. Fredrickson BL. What good are positive emotions? Rev Gen Psychol. 1998; 2: 300-319. doi:10.1037/1089-2680.2.3.300

14. Fredrickson BL. The role of positive emotions in positive psychology. Am Psychol. 2000; 56: 218226.

15. Hien D, Litt LC, Cohen LR, Miele GM, Campbell A. Trauma services for women in substance abuse treatment: An integrated approach. Washington, DC: American Psychological Association; 2009. http://dx.doi.org.proxy1.athensams.net/10.1037/11864-000

16. Koole SL. The psychology of emotion regulation: An integrative review. Cogn Emot. 2009; 23: 441.

17. van't Wout $M$, Chang LJ, Sanfey AG. The influence of emotion regulation on social interactive decision-making. Emotion. 2010; 10: 815-821. http://dx.doi.org/10.1037/a0020069

18. Gratz KL, Roemer L. Multidimensional assessment of emotion regulation and dysregulation: Development, factor structure, and initial validation of the difficulties in emotion regulation scale. J Psychopathol Behav. 2004; 26: 41-54. 
19. Burns EE, Fischer S, Jackson JL, Harding HG. Deficits in emotion regulation mediate the relationship between childhood abuse and later eating disorder symptoms. Child Abuse Neglect. 2012; 36: 32-39.

20. Gratz KL, Tull MT, Baruch DE, Bornovalova MA, Lejuez CW. Factors associated with co-occurring borderline personality disorder among inner-city substance users: the roles of childhood maltreatment, negative affect intensity/reactivity, and emotion dysregulation. Compr Psychiat. 2008; 49: 603-618.

21. Treasure J, Schmidt U. The cognitive-interpersonal maintenance model of anorexia nervosa revisited: A summary of the evidence for cognitive, socioemotional and interpersonal predisposing and perpetuating factors. J Eat Disord. 2013; 1: 1-10.

22. Wildes JE, Marcus MD. Development of emotion acceptance behavior therapy for anorexia nervosa: A case series. Int J Eat Disord. 2011; 44: 421-427.

23. Vettese LC, Dyer CE, Li WL, Wekerle C. Does self-compassion mitigate the association between childhood maltreatment and later emotion regulation difficulties? A preliminary investigation. Int J Ment Health Addict. 2011; 9: 480-491. doi:10.1007/s11469-011-9340-7

24. Cummings ME, Davies PT, Campbell SB. Developmental psychopathology and family process: Theory, research, and clinical implications. New York: Guilford Press; 2000.

25. Gilbert P., Procter S. Compassionate mind training for people with high shame and self-criticism: overview and pilot study of a group therapy approach. Clin Psychol Psychot. 2006; 13: 353-379.

26. Johnson CF. Child sexual abuse. Lancet. 2004; 364: 462-470.

27. Dearing RL, Stuewig J, Tangney JP. On the importance of distinguishing shame from guilt: Relations to problematic alcohol and drug use. Addict Behav. 2005; 30: 1392-1404.

28. Adams KM, Robinson DW. Shame reduction, affect regulation, and sexual boundary development: Essential building blocks of sexual addiction treatment. Sex Addict Compuls. 2001; 8: 23-44.

29. Wilson KG, Hayes SC, Byrd MR. Exploring compatibilities acceptance and commitment therapy and 12-step treatment for substance abuse. J Ration Emot Cogn Behav Ther. 2000; 18: 209-234.

30. Stice E. Risk and maintenance factors for eating pathology: A meta-analytic review. Psychol Bull. 2002; 128: 825-848.

31. Khantzian E. The self-medication hypothesis of substance use disorders: A reconsideration and recent applications. Harvard Rev Psychiat. 1997; 4: 231-244.

32. Thorberg FA, Lyvers M. Negative mood regulation (NMR) expectancies, mood, and affect intensity among clients in substance disorder treatment facilities. Addict Behav. 2005; 31: 811- 820.

33. Suh JJ, Ruffins S, Robins CE, Albanese MJ, Khantzian EJ. Self-medication hypothesis: Connecting affective experience and drug choice. Psychoanal Psychol. 2008; 25: 518-532. http://dx.doi.org/10.1037/0736-9735.25.3.518

34. Finlay-Jones AL. The relevance of self-compassion as an intervention target in mood and anxiety disorders: A narrative review based on an emotion regulation framework. Clin Psychol. 2017; 21 : 90-103.

35. Grzywacz JG, Almeida DM Stress and binge drinking: A daily process examination of stressor pileup and socioeconomic status in affect regulation. Int J Stress Manage. 2008; 15: 364-380. http://dx.doi.org/10.1037/a0013368 
36. Odou N., Brinker J. Exploring the relationship between rumination, self-compassion, and mood. Self Ident. 2014; 13: 449-459.

37. Kurtz E, Ketcham K. The spirituality of imperfection. New York: Bantam Books; 1992.

38. Neff KD. The development and validation of a scale to measure self-compassion. Self Ident. 2003; 2: $223-250$.

39. Gilbert P. The origins and nature of compassion focused therapy. Br J Clin Psychol. 2014; 53: 6-41.

40. Gilbert P. Introducing compassion-focused therapy. Adv Psychiatr Treat. 2009; 15, 199-208.

41. Inwood E, Ferrari M. Mechanisms of change in the relationship between self-compassion, emotion regulation, and mental health: A systematic review. Appl Psychol Health Well Being. 2018; 10: 215-235.

42. Folkman S, Moskowitz JT. Positive affect and the other side of coping. Am Psychol. 2000; 55: 647654.

43. Isen AM. Some perspectives on positive affect and self-regulation. Psychol Inq. 2000; 11: 184-188.

44. Fong M, Loi NM. The mediating role of self-compassion in student psychological health. Aust Psychol. 2016; 51: 431-441.

45. Morley RH. Violent criminality and self-compassion. Aggress Violent Beh. 2015; 24: 226-240.

46. Lawrence V, Lee D. An exploration of people's experiences of compassion-focused therapy for trauma, using interpretative phenomenological analysis. Clin Psychol Psychother. 2013. http://doi.org/10.1002/cpp.1854

47. Gilbert P. Compassion and cruelty: A biopsychosocial approach. In: Gilbert P, editor. Compassion: Conceptualisations, research and use in psychotherapy London: Routledge; 2005. pp. 9-74.

48. Gratz K, Tull MT. The relationship between emotion dysregulation and deliberate self-harm among inpatients with substance use disorders. Cogn Ther Res. 2010; 34: 544-553.

49. Nikmanesh Z, Kazemi Y, Khosravy M. Study role of different dimensions of emotional selfregulation on addiction potential. J Family Reprod Health. 2014; 8: 69-72.

50. Kassel JD. Veilleux JC. Introduction: The complex interplay between substance abuse and emotion. In: Kassel JD, editor. Substance abuse and emotion. Washington, DC: APA; 2010. pp. 3-12.

51. Kober H. Emotion regulation in substance use disorders. In: Gross, J, editor. Handbook of emotion regulation. 2nd ed. New York, NY: Guilford Press; 2014. pp. 428-446.

52. Graham C. Examining the role of self-compassion in acceptance and commitment therapy with substance abusing population. Louisville, KY: Spalding University; 2016.

53. Brooks M, Kay-Lambkin F, Bowman J, Childs S. Self-compassion amongst clients with problematic alcohol use. Mindfulness. 2012; 5: 308-317.

54. Rendon KP. Understanding alcohol use in college students: A study of mindfulness, selfcompassion, and psychological symptoms. Austin, TX: University of Texas at Austin; 2006.

55. Fredrickson BL, Losada MF. Positive affect and the complex dynamics of human flourishing. Am Psychol. 2005; 60: 678-686. doi:10.1037/0003-066X.60.7.678

56. Fredrickson BL. The role of positive emotions in positive psychology: The broaden-and-build theory of positive emotions. Am Psychol. 2001; 56: 218-226.

57. Neff KD. Self-compassion, self-esteem, and well-being. Soc Personal Psychol Compass. 2011; 5: 112. 
58. Crocker J, Canevello A, Breines JB, Flynn H. Interpersonal goals and change in anxiety and dysphoria in first-semester college students. J Pers Soc Psychol. 2010; 98: 1009-1024.

59. MacBeth A, Gumley A. Exploring compassion: A meta-analysis of the association between selfcompassion and psychopathology. Clin Psychol Rev. 2012; 32: 545-552. doi: http://dx.doi.org/10.1016/j.cpr.2012.06.003

60. Kobau R, Seligman MEP, Peterson C, Diener E, Zack MM, Chapman D. et al. Mental health promotion in public health: Perspectives and strategies from positive psychology. Am J Public Health. 2011; 101: 1-9.

61. Cloud W, Granfield R. Conceptualizing recovery capital: Expansion of a theoretical construct. Subst Use Misuse. 2008; 43: 1971-1986.

62. Chen G. Social support, spiritual program and addiction recovery. Int J Offender Ther. 2006; 50: 306-323.

63. Narcotics Anonymous World Services, Inc. Narcotics anonymous. 6th ed. Chatsworth, CA: Narcotics Anonymous World Services, Inc.; 2008.

64. Ellis A. Psychotherapy and the value of a human being. Handbook of rational-emotive therapy. New York, NY: Springer; 1977. pp. 99-112.

65. Alcoholics Anonymous World Services. Alcoholics anonymous: The story of how many thousands of men and women have recovered from alcoholism. 4th ed. New York, NY; 2001.

66. Treeby M, Bruno R. Shame and guilt-proneness: Divergent implications for problematic alcohol use and drinking to cope with anxiety and depression symptomatology. Pers Indiv Differ. 2012; 55 : 613-617.

67. Breines JG, Chen S. Activating the inner caregiver: The role of support-giving schemas in increasing state self-compassion. J Exp Soc Psychol. 2013; 49: 58-64. doi:http://dx.doi.org/10.1016/j.jesp.2012.07.015

68. Niebuhr R. The serenity prayer. In: Beck EM, editor. Bartlett's familiar quotations. 15th ed. Boston: Little, Brown; 1980.

69. Newcombe SR. Shame and self-compassion in members of Alcoholics Anonymous. Wright Institute Graduate School of Psychology, Berkeley, California; 2015.

70. Chen G. The meaning of suffering in drug addiction and recovery from the perspective of existentialism, Buddhism and the 12-Step program. J Psychoactive Drugs. 2010; 42: 363-75. doi:10.1080/ 02791072.2010.10400699.

71. Coyhis D, White W. Addiction and recovery in native America: Lost history, enduring lessons. Counselor. 2002; 3: 16-20.

72. World Health Organization. Basic documents. 43rd ed. Geneva: World Health Organization; 2001.

73. Neff K., Germer CK. A pilot study and randomized controlled trial of the mindful self-compassion program. J Clin Psychol. 2013; 69: 28-44.

74. Smeets E, Neff K, Alberts H, Peters M. Meeting suffering with kindness: Effects of a brief selfcompassion intervention for female college students. J Clin Psychol. 2014; 70: 794-807. doi:10.1002/jclp.22076

75. White W, Cloud W. Recovery capital: A primer for addictions professionals. Counselor. 2008; 9: 22-27. 


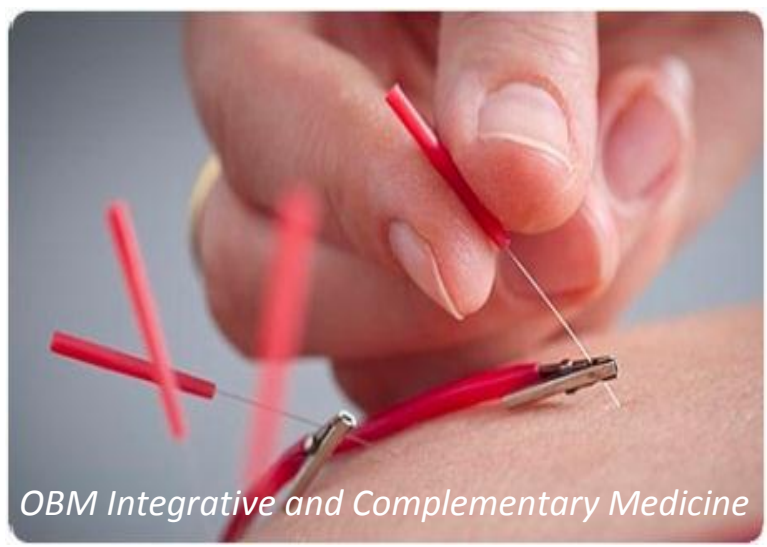

Enjoy OBM Integrative and Complementary Medicine by:

1. Submitting a manuscript

2. Joining in volunteer reviewer bank

3. Joining Editorial Board

4. Guest editing a special issue

For more details, please visit:

http://www.lidsen.com/journals/icm 